\title{
DISTINTAS APROXIMACIONES A LA ELECCIÓN RACIONAL
}

\author{
JOSÉ SATURNINO MARTÍNEZ GARCÍA \\ Universidad de La Laguna
}

\author{
PALABRAS CLAVE ADICIONALES \\ ADDITIONAL KEYWORDS \\ Teoría social, Acción racional, Metodología. \\ Social Theory, Rational Action, Methodology.
}

\begin{abstract}
RESUMEN. En este artículo se realiza una clasificación de las teorías de la elección racional. La elección racional instrumentalista dice que la teoría es buena si sus predicciones teóricas son buenas, sin importar si la teoría es cierta o falsa. La elección racional realista considera que la teoría de la elección racional es cierta, pero que necesita de otros supuestos, tomados normalmente de la psicología, como la teoría cognitivista. La reconstrucción racional de la acción, enmarcada en la tradición weberiana, considera la elección racional como una forma de comprender la acción social mediante empatía, atribuyéndole sentido. La reconstrucción formal afirma que la elección racional no es realmente una teoría, sino simplemente una gramática útil para pensar los problemas sociales. La reconstrucción estadística defiende que la elección racional es buena para explicar un tipo ideal de actor, representativo de un conjunto: cada actor puede ser diferente, pero las restricciones institucionales producen regularidades empíricas para el conjunto.
\end{abstract}

SUMMARY. An introduction to rational choice is included in this paper and a rational choice theories classification is later explained. The instrumentalist rational choice states that the theory is acceptable if its theoretical predictions are valid, regardless of whether the theory is correct or incorrect. The realist rational choice considers that the rational choice is correct, but that it requires other suppositions, normally taken from psychology, such as the cognitive theory. Rational reconstruction of the action, framed in the weberian tradition, considers rational choice as a way of understanding social action by means of empathy, ascribing meaning to it. Formal reconstruction asserts that the rational choice is not really a theory, but simply a useful grammar to consider the social problems. Statistic reconstruction upholds that the rational choice is valid to explain an ideal type of actor, representative of a group; each actor can be different, but the institutional restrictions produce empirical regularities for the group.

E-mail: josamaga@ull.es

Revista Internacional de Sociología (RIS)

Tercera Época, № 37, Enero-Abril, 2004, pp. 139-173. 
Cuando en el ámbito de las ciencias sociales se habla de teoría de la elección racional, ¿de qué elección racional se trata? Quizá ésta sea la primera pregunta que debamos hacer a alguien que quiera defender o criticar esta orientación teórica de las ciencias sociales. La tesis que se sostiene en este artículo es que realmente hay varias formas de entender la elección racional, y que parte de los debates que hay en torno a ella tienen bastante de diálogo de sordos, debido a que quienes emplean la misma expresión, están pensando en cosas distintas. Por tanto, aquí más que resolver polémicas en torno a la elección racional, intentaremos disolverlas.

En primer lugar, haremos una breve exposición de lo que podemos considerar como los argumentos básicos de la elección racional, corriente básica en economía, con gran fuerza en la ciencia política estadounindense, y polémica, pero con peso, en otras disciplinas sociales, como la sociología. Básicamente, podemos resumir todas las orientaciones de la elección racional en tres argumentos básicos:

$\left.1^{\circ}\right)$ los individuos toman decisiones racionales con arreglo a fines,

$2^{\circ}$ ) dadas sus preferencias (elemento subjetivo de la acción) y

$3^{\circ}$ ) teniendo en cuenta cuáles son las restricciones en las que pueden tomar sus decisiones (elemento objetivo de la acción).

A continuación expondremos las distintas defensas que pueden hacerse de estos argumentos, y veremos que cada defensa tiene sus puntos fuertes y sus puntos débiles, pero que son distintos. Tras este repaso, expondremos cuáles consideramos que son las principales críticas infundadas y cuáles las principales críticas adecuadas a la elección racional.

\section{ALGUNAS NOTAS GENERALES SOBRE LAS TEORÍAS DE LA ELECCIÓN RACIONAL}

Bajo el nombre de elección racional se engloban una serie de perspectivas teóricas de las distintas ciencias sociales que comparten las siguientes características (Goldthorpe, 1998a).

En primer lugar, su compromiso con el individualismo metodológico, es decir, aceptar que los fenómenos sociales deben explicarse a partir de acciones de los individuos. En un ejemplo ya canónico, Coleman (1990) ilustra este argumento recurriendo al estudio clásico de Weber sobre la relación entre ética protestante y desarrollo capitalista. Considera Coleman que, si deseamos relacionar dos hechos macro, como la ética protestante y el desarrollo del capitalismo, debemos hacerlo a través de lo micro: cómo la ética calvinista (nivel macro) proporciona una serie de valores a los individuos (nivel micro), que actuando en búsqueda de señales para su salvación eterna (nivel micro), producen como efecto no querido un tipo de relaciones sociales que facilita el desarrollo del capitalismo (nivel macro). La 
explicación podrá enfatizar alguna de las uniones entre estos nodos macro y micro, pero no saltársela, de tal modo que no se puede ir directamente de lo macro a lo macro $^{1}$. Este individualismo metodológico no necesariamente es ontológico, esto es, se puede reconocer la existencia de otras entidades sociales que no pueden descomponerse en última instancia sólo en el agregado de individuos que la componen. Lo importante es el fundamento micro de las explicaciones sociales. Por supuesto, tampoco afirma que todos los procesos sociales sean resultado de acciones conscientes de los individuos. De hecho, uno de los campos de estudio más propiamente sociológico es el de los efectos no queridos de la acción o resultados emergentes de agregados individuales (es decir, resultados que son distintos a la suma de las partes), como hemos señalado en el clásico estudio de Weber sobre ética protestante y espíritu del capitalismo.

En segundo lugar, las teorías de la elección racional dan cuenta del comportamiento suponiendo en principio que la acción social es elección racional: "dados los medios de que dispone el individuo y sus fines, tratará de alcanzarlos de la mejor forma posible. El investigador debe esforzarse en buscar esta racionalidad instrumental en las prácticas que pretende explicar, a pesar de que a primera vista parezcan conductas irracionales. El mérito de la racionalidad como principio explicativo se debe a que cumple las virtudes de la navaja de Ockham: si podemos dar cuenta de una acción diciendo que es racional no necesitamos añadir más hipótesis: "El privilegio explicativo de la racionalidad se basa en dos razones: [...] la racionalidad está supuesta por cualquier teoría de la motivación, mientras que la racionalidad misma no supone nada más [y] aunque la racionalidad puede tener sus problemas, la oposición está en peores condiciones" (Elster, 1989b: 34). El segundo razonamiento quiere decir básicamente que la "oposición" debe establecer tantas hipótesis accesorias y es tan dificil comprobar sus supuestos, que poco en claro aporta. En sentido parecido se expresa Esser (1996: 164), al razonar sobre la relación entre elección racional y análisis estadístico, cuando parafrasea a Churchill para afirmar que la elección racional es la menos mala de las teorías disponibles.

Estos principios básicos pueden entenderse como una teoría general de la acción, que relaciona lo objetivo, lo subjetivo y su síntesis, las acciones sociales ${ }^{2}$. Lo objetivo se refiere a las restricciones a la acción, como veremos más adelante. Lo subjetivo es entendido como las preferencias de los actores, incluyendo la interpretación que hagan de la situación. Las acciones son producto de esta relación entre lo objetivo y lo subjetivo, un producto mediado por la racionalidad instrumental. Relacionamos acciones, preferencias y restricciones mediante dicha

\footnotetext{
${ }^{1}$ Bunge (2000) considera que realmente este modelo explicativo no es individualista, sino sistémico. Con este adjetivo se refiere Bunge a una perspectiva teórica que considera a los individuos, las relaciones entre ellos y el ambiente y los estados emergentes que generan estas relaciones.

${ }^{2}$ Este párrafo deriva de comunicaciones verbales de Julio Carabaña.
} 
RIS

REVISTA INTERNACIONAL DE SOCIOLOCIA

№ 37, ENERO-ABRIL, 2004

JOSÉ SATURNINO MARTÍNEZ GARCÍA

racionalidad instrumental, pues suponemos que el agente elige entre varios cursos posibles de acción, intentando maximizar su utilidad (o minimizar sus costes) sujeta a restricciones. El esquema explicativo habitual consiste en dar prioridad a las restricciones, dejando invariantes las preferencias, tanto entre individuos como en un mismo individuo a lo largo del tiempo, o justificando fuertemente sus variaciones, pues, de no ser así, proliferarían las hipótesis ad hoc, mediante el sencillo recurso de variar las preferencias según convenga. Elster (1989a; 2000) también plantea que la relación entre esta tríada puede ser variable, pues las acciones pueden modificar las preferencias (comportamientos deliberados para modificar los gustos o el carácter) o las restricciones (como las inversiones). Asimismo, las restricciones pueden determinar las preferencias (preferencias sobreadaptativas, como en la fábula de la zorra y las uvas, mecanismos de disonancia cognitiva ${ }^{3}$ ). Como iremos viendo, la consideración de lo objetivo (las restricciones o escasez) y lo subjetivo (las preferencias) plantea distintos problemas.

\section{LA ESCASEZ}

Hablamos de escasez para poder dar cuenta de todas aquellas decisiones que el individuo puede tomar, y que necesariamente están limitadas. Por ello se habla también de conjunto factible o espacio de elección. La escasez es uno de los supuestos básicos tanto de la economía positiva como de la elección racional ${ }^{4}$. Es un concepto bidimensional: objetivo y subjetivo. Por el lado objetivo hace referencia a los recursos que puede movilizar el actor. Por el lado subjetivo hace referencia al desajuste entre deseos y oportunidades, oportunidades limitadas por esos recursos objetivos. La dimensión objetiva es causa necesaria para que haya escasez, mientras que la definición subjetiva es causa suficiente. La escasez, en términos económicos, quiere decir que siempre que se quiere un bien, habrá que renunciar a algún otro para conseguirlo: nada es gratis. La mezcla de objetividad

\footnotetext{
${ }^{3}$ Las preferencias sobreadaptativas son aquellas en las que "de la necesidad se hace virtud". Es decir, situaciones de conformismo forzado ante la dificultad objetiva para modificarlas. Una situación de este tipo se da en la fábula de la zorra y las uvas: cuando la zorra se da cuenta que no alcanza las uvas que desea, se va mascullando que en realidad las uvas todavía no están maduras, y que no valía la pena conseguirlas (Elster, 1983). Por otra parte, la disonancia cognitiva se produce cuando, pudiendo elegir entre dos situaciones de valor parecido, una vez que optamos por una de ellas ya no podemos optar por la anterior (por ejemplo, elegir entre dos carreras). Por economía psíquica, para no vivir en la continua tensión de "qué hubiese pasado si hubiese elegido la otra opción", se tiende a valorar más positivamente la opción elegida y a considerar más negativa la opción rechazada, sobre la que ya no se puede volver.

4 "En la economía pura examinamos la implicación de la existencia de medios escasos con usos alternativos” (Robbins, 1935).
} 
y subjetividad nos produce un concepto relativo, ya que alguien que viva en la opulencia puede percibir escasez en su estilo de vida, mientras que otra persona en la pobreza puede que no la perciba de forma tan intensa.

Hay quienes ponen en cuestión este supuesto de la escasez. Sahlins (1972), por ejemplo, se refiere a las sociedades de cazadores y recolectores (los bosquimanos en particular) como "sociedades de la abundancia", en tanto que subexplotan las posibilidades alimentarias de su entorno, y los esfuerzos por subsistir les requieren pocas horas al día. Pero esto no quiere decir que en dicho mundo no haya que tomar unas decisiones sujetas a ciertos grados de libertad. Como le replica Godelier (1984: 62), están limitados por no poder almacenar ni víveres ni agua, y bajo estas restricciones organizan sus actividades.

La escasez como concepto plantea cierta confusión, pues hablando castellano correctamente, "escasez" no es "una situación en la cual las necesidades y deseos de un individuo o grupo de individuos exceden los recursos disponibles para ser satisfechos [...] En el uso que los economistas hacen del término, la escasez se presenta en cualquier sociedad en la cual haya alguien cuyos deseos no estén completamente satisfechos" (Bannock et al., 1992). En castellano se entiende por "escasez" "pobreza o falta de lo necesario para subsistir" (acepción más acorde con lo aquí discutido de las tres que proporciona el diccionario de la Real Academia Española de la Lengua en su edición de 1992). Desde esta perspectiva, es evidente que, mientras no haya gente que muera de hambre, no hay escasez y, por tanto, este supuesto se vuelve más bien arbitrario. Sin embargo, desde la perspectiva teórica, mientras tengamos que renunciar a un posible curso de acción para seguir otro, sí hay escasez.

En general, puede considerarse que el supuesto de la escasez, entendida como desajuste entre deseos y oportunidades, es "natural", es decir, que en toda sociedad hay escasez, aunque los bienes considerados escasos (la percepción del desajuste) estén determinados históricamente. Por esto, nos cuesta entender el siguiente exceso de constructivismo social: "La escasez es un fenómeno coyuntural que no puede ser tomado como punto de partida de la reflexión sobre valores y precios [...] Se propone como 'objetivamente dada' la distancia entre necesidades subjetivas y los recursos disponibles" (González León, 1996: 11). Por supuesto que aquello que se considere escaso está históricamente determinado, así como la forma de hacer frente a dicha escasez, pero cuesta imaginar, no ya una sociedad parecida a alguna de las conocidas en la Historia, sino incluso una utopía, en la que no exista escasez (en sentido económico) de ningún tipo. Por tanto, la escasez sí es un primer paso necesario para el pensamiento económico. En lo que sí tiene razón González es en considerar que la reflexión sobre los precios no debe agotarse en el principio natural de la escasez, pero es una reflexión que sólo resulta pertinente en ciertos planos teóricos.

Elster dedica uno de sus más recientes libros a estudiar en profundidad la escasez (Elster, 2002), analizando hasta qué punto "menos es más", es decir, 
RIS

REVISTA INTERNACIONAL DE SOCIOLOCIA

N 37, ENERO-ABRIL, 2004

JOSÉ SATURNINO MARTÍNEZ GARCÍA

los agentes pueden decidir restringir su espacio de elección, vivir en una mayor escasez, porque a cambio de esto obtendrán una mayor recompensa. El ejemplo clásico es el de Ulises y las sirenas (ya estudiado anteriormente por Elster (1979)), el ejemplo práctico es el de ir a una biblioteca a estudiar o estudiar con un compañero más responsable que uno mismo, para no ceder a ociosas tentaciones. Pero si la escasez está dada a los agentes, o los agentes la pueden variar (mediante restricciones adicionales o mediante inversiones), no afecta a la validez teórica de la elección racional.

Lo que sí es pertinente desde una perspectiva teórica es la demostración que hace Becker (197.1) de que no es relevante si los agentes se comportan o no racionalmente con arreglo a sus restricciones, sino que un conjunto de agentes se comportará como lo haría un agente racional. Esta demostración la hace como prueba de la ley de la demanda "si sube el precio de un bien normal, baja su demanda". Si las familias son insensibles al aumento del precio, habrá familias que aunque quieran no podrán mantener el nivel de consumo previo a esa variación del precio, pues ya no tienen el mismo poder de compra. Por otro lado, si las familias se comportan sin observar los precios, de forma totalmente aleatoria, dado que el bien es más caro, será más improbable que lo compren; habrá familias que movidas por la costumbre o por su comportamiento errático mantengan el nivel de consumo previo a la variación de los precios, pero dado que el bien es más caro (y, ceteris paribus, no se ha incrementado la renta familiar) habrá familias que ya no puedan mantener ese nivel de consumo, por lo que la demanda final del bien cae. Como vemos, este comportamiento racional del agregado es independiente de las motivaciones del comportamiento particular de cada familia. Es decir, el conjunto se comporta racionalmente (consume menos de un bien normal cuyo precio ha subido), aunque no lo hagan sus partes.

Tras estas aclaraciones sobre las restricciones y los espacios de elección, no caben afirmaciones que evidentemente resultan de una confusión conceptual sorprendente o de un esfuerzo sin sentido por llevar al absurdo las debilidades de la elección racional. Nos referimos a afirmaciones del tipo de que "un millonario y un vagabundo" disfrutan de la misma utilidad, ya que ambos eligen racionalmente lo que quieren (Zafirovsky, 1999: 78). A poco que se esté familiarizado con la elección racional, se sabe que lo que se deriva de estas teorías es que, a distintos espacios de elección, corresponden distintos niveles de utilidad, no que por elegir racionalmente, todos alcancen el mismo nivel de utilidad.

Tras lo visto, podemos afirmar que los agentes siempre toman decisiones en un contexto de escasez, entendida ésta como la imposibilidad de realizar dos acciones incompatibles o como desajuste entre deseos y recursos. Este elemento universal de la escasez no quita que la forma en que se materializa esté históricamente determinada. Por otro lado, las restricciones se imponen de tal forma a un conjunto de agentes, que pueden hacer que el resultado de las decisiones agregadas pueda interpretarse como racional por un observador externo, como ocurre con la ley de la demanda. 


\section{PREFERENCIAS}

Una vez analizado el filtro objetivo del comportamiento humano (el conjunto de oportunidades que se manifiesta por el principio de escasez), en este apartado veremos el filtro subjetivo. Este filtro subjetivo, como hemos dicho, son las preferencias individuales, que pueden medirse a través de la utilidad que proporcionan al agente determinadas decisiones.

Teóricamente, las preferencias se definen como una relación ordinal de distintos estados entre los que el individuo puede elegir. Dada una alternativa entre dos elementos simples (un bien) o compuestos (una cesta de bienes), pudiendo generalizar los bienes a estados o situaciones, el individuo sabe cuál es el par de la comparación que prefiere. Este interés por representar las preferencias como una ordenación, y no como una relación cardinal, se debe a que, en una ordenación, no se manifiesta la intensidad de preferencias ni, por tanto, es necesario especificar una magnitud que indique cuántas veces se prefiere un elemento de la comparación al otro.

Las preferencias, para permitir una elección racional, deben cumplir tres supuestos, que permiten su ordenación: ser reflexivas, completas y transitivas.

- Reflexivas: cada elemento es comparable consigo mismo. Supuesto trivial, pero axioma necesario para poder construir unas reglas consistentes de elección.

- Completas: cualquier conjunto de elementos que se presente es comparable, es decir, cualquier conjunto posee alguna característica común en mayor o menor medida, característica representable normalmente por dinero o por tiempo. En los ámbitos más propios de la economía este supuesto no suele presentar ningún problema, pues podemos mantener que la característica común medida es simplemente el precio monetario. Sin embargo, no está claro que todo se pueda comparar, especialmente cuando no se dispone de información suficiente para valorar adecuadamente cada opción. Elster (1989a) toma como ejemplo de un caso de información insuficiente la elección de estudios superiores. En una situación como ésta, la decisión pasa a hacerse no por el valor de estas alternativas inconmensurables, sino de elementos asociados a ellas que son comparables, como por ejemplo, si un grupo de amigos decide o no cursar los mismos estudios, cercanía del domicilio particular, etc. Un problema ligeramente distinto estriba en que se supone que se compara sólo una característica común al conjunto de elementos. Pero si existe más de una característica y no hay una dominancia clara entre ellas, puede resultar que este axioma no se ajuste bien a la realidad, pues unas veces se puede decantar por aplicar un criterio de comparación y otras, otro. Además, para que este axioma pueda funcionar correctamente, también es necesario suponer que las preferencias son estables, pues si estuviesen cambiando continuamente, tampoco podrían compararse, ya que en el caso extremo, en el tiempo transcurrido entre una comparación y la siguiente, por breve que fuese, ya habrían variado las preferencias. 


\section{RIS}

- Transitivas: si se prefiere $A$ a $B, B$ a $C$, se prefiere $A$ a $C(A>B \wedge B>C \Rightarrow A>C)^{5}$. Esta condición, junto con las dos anteriores, es lógicamente necesaria para poder ordenar preferencias; de no cumplirse no sabríamos qué se prefiere, si $A$ o $C$. Este supuesto es razonable en el caso de la ordenación de preferencias individuales (no en la ordenación de las colectivas ${ }^{6}$ ), aunque, a su vez, necesita de otro supuesto. Hay quien considera invalidado este axioma debido a que se manifiestan distintas ordenaciones de preferencias en distintos contextos sociales: puede que no se manifiesten las mismas preferencias ante la novia que ante la abuela, ante el jefe que ante el hijo, etc. (Ibáñez, 1988). En realidad no estaríamos variando las preferencias, cabría argüir. Ocurre más bien que, dependiendo de los contextos sociales, tomar una misma decisión puede representar costes y beneficios distintos.

La "transitividad" es el supuesto más fuerte de los barajados, pero sin él, no se pueden ordenar las preferencias y por tanto no puede haber una elección racional, ya que no se sabe realmente cuál es la mejor decisión. Es fuerte debido a otra cuestión: la independencia de las alternativas irrelevantes. Este supuesto nos dice que si debemos comparar entre $\mathrm{A}$ y $\mathrm{B}$, y preferimos $\mathrm{A}$, si luego debemos comparar entre A, B y C, seguiremos prefiriendo A a B; es decir, nuestra ordenación de las alternativas no se ve afectada por una tercera. Esto plantea problemas, pues no considera la intensidad de las preferencias. Estos problemas se detectan especialmente en casos de elección colectiva, como estudia Coleman (1990), entre otros. El ejemplo con el que este autor los ilustra es el siguiente: en unas primarias del partido demócrata se presentan dos candidatos, uno blanco y otro negro. El candidato negro es preferido al blanco y en el voto hay una dimensión racial. Si se presenta un tercer candidato negro, esto puede sustraerle más votos al candidato negro que al candidato blanco, saliendo ganador el candidato blanco. Lo que ocurre es que en la ordenación de preferencias no se tiene en cuenta la intensidad de las mismas, así como se supone que se establecen sobre una única dimensión, en tanto que los dos candidatos negros son más parecidos, la intensidad de preferencias no es tan fuerte como con respecto al blanco.

Los axiomas básicos producen un espacio de preferencias unidimensionales denominado como "racionalidad arquimédica" sobre las preferencias (Van Parijs (1990), citado por Gil Calvo (1993)). Este modelo axiomático plantea al menos dos problemas relevantes. Uno, la falta de realismo que supone considerar que

\footnotetext{
${ }^{5}$ Por simplificar, nos limitamos a la transitividad fuerte, la débil establece mayor o igual, en vez de estrictamente mayor.

${ }^{6}$ Arrow demostró mediante su teorema de posibilidad (o imposibilidad) que la agregación de preferencias individuales puede producir preferencias intransitivas. A través de ensayos, se ha llegado a la regla empírica siguiente: de las posibles ordenaciones de preferencias resultantes de agregar individuos, un poco menos del $10 \%$ resultan circulares o cíclicas, cuando hay tres alternativas y 25 personas o más deben elegir (Sen, 1970: 200).
} 
las personas pueden ordenar sus preferencias sobre una única dimensión, con un único criterio (supuesto implícito en la "completitud" y en la transitividad) y de forma estable en el tiempo. El otro, no disponer de una medida de las preferencias independiente de las elecciones, lo que nos lleva a la falacia de la petición de principio, es decir, se da por supuesto lo que se quiere demostrar mediante el razonamiento circular de que lo preferido es lo que ha sido elegido porque es lo preferido.

En lo que se refiere a la falta de unidimensionalidad en el mundo real (esto es, no poder ordenar todas las elecciones posibles bajo una única dimensión invariante), se han planteado al menos dos posibles soluciones. Una de ellas la podríamos etiquetar como de ordenaciones lexicográficas. La otra, la descomposición del actor en acciones.

Una ordenación lexicográfica, como su propio nombre indica, consiste en ordenar con criterios alfabéticos: no se comparan todos los atributos de cada estado sobre el que se debe decidir, de tal manera que más cantidad de uno de ellos pueda suplir la menor cantidad de otro. Por ejemplo, si una palabra empieza por $a$ irá antes que otra que empiece por $b$, aunque la que empiece por $a$ esté seguida sólo por letras $z$ y la que empiece por $b$ lo esté de $a$. Este tipo de ordenaciones son claras en situaciones en las que se roza la supervivencia: si me estoy muriendo de sed prefiero medio litro de agua y un $C D$ de mi música favorita a un cuarto litro de agua y millones de $C D$ 's de mi música favorita. Podemos considerar en esta línea las propuestas de Pizzorno (1989). La identidad para Pizzorno o los "múltiples yo" es el primer criterio de la ordenación, una vez que ese criterio queda definido pueden compararse de forma "arquímedea" el resto de alternativas.

Frankfurt (1971) y Harsanyi (1955) hablan de metapreferencias y de preferencias éticas respectivamente para referirse a un problema similar, es decir, a un tipo de preferencias superior que ordena otro tipo de preferencias. Por ejemplo, decidir una identidad, como ser monje de clausura, ordena mis preferencias sobre innumerables cuestiones. Pero esta estrategia explicativa nos plantea el problema de la regresión infinita, pues habría preferencias de tercer orden para elegir entre preferencias de segundo orden, y así sucesivamente. Como señala Hollis (1994), es difícil salir de esta espiral sin salir del individualismo metodológico.

Para solucionar este problema, Gil Calvo (1993) adopta la otra estrategia - la descomposición en acciones-, a partir de Simon (1989), pues considera que lo que se debe descomponer no es el yo (estrategia poco realista y difícilmente operacionalizable), sino descomponer las acciones, y tener en cuenta que, en distintas acciones, pueden funcionar distintos criterios de ordenación que dependerán del contexto, según los estudios de Simon sobre racionalidad limitada. Pero esto nos lleva a la cuestión que ya señalamos en la crítica de Ibáñez a la transitividad: en distintos contextos se puede elegir de forma distinta, bien porque se modifiquen las preferencias, bien porque se modifiquen los costes o los beneficios de la acción, o ambos, así que no podemos discriminar claramente qué varía, las 
RIS

REVISTA INTERNACIONAL DE SOCIOLOGIA

№ 37, ENERO-ABRIL, 2004

JOSÉ SATURNINO MARTÍNEZ GARCIA

restricciones o las preferencias. Gil Calvo no aclara cómo podemos saber si lo que varían son los costes de las acciones o su utilidad ¿Qué criterio externo a las acciones empleamos para saber si son racionales? Por parsimonia explicativa, consideramos que varían las restricciones, pues, en general, su medición es más fácil que la de las preferencias, como veremos. Y debido a que, si asumimos que las preferencias cambian con gran facilidad o que, según el tipo de acciones, se modifica la racionalidad sustantiva, se desmorona la potencia explicativa de la elección racional, quedando reducida a un mero artefacto reconstructivo post-hoc y antológico en el que pura tautología, en la que se hace lo que se prefiere, se prefiere lo que se hace. Así que la alternativa viable teóricamente - el contexto varía-, nos lleva a la solución beckeriana (que veremos luego) basada en el hecho de que de gustibus non est disputandum, por lo que la solución de Gil Calvo, no es productiva como estrategia explicativa o, de serlo, no aporta nada nuevo.

Sigamos con la otra cuestión, la medición de las preferencias. Preferencias y elecciones no pueden medirse independientemente (por ejemplo, Heath 1976: 80). No observamos las preferencias de los agentes, sino sus elecciones $y$, a partir de las elecciones, inferimos sus preferencias. Esto supone un problema explicativo, pues si intentamos dar cuenta de las elecciones en función de las preferencias, y como medida de las preferencias consideramos las elecciones, hay una confusión entre explanans y explanandum, pues la misma variable forma parte de ambos (Rosenberg 1992). Es como si intentásemos decir que llueve cuando en las nubes el agua está muy condensada, y tomásemos como media de la condensación los metros cúbicos de agua recogidos después de llover... Siguiendo a Heath (1976: 83), hay dos posibilidades para no caer en la tautología: adoptar una posición conductista, abandonando el principio de maximización como tautológico y reemplazándolo con supuestos sobre la elección en ámbitos concretos, sin establecer generalidades, como hace Homans. O definir la utilidad subjetivamente, junto con instrumentos para medirla.

Esta segunda línea nos lleva a la atribución de preferencias, de forma que las elecciones sean coherentes con las preferencias atribuidas (Sánchez-Cuenca, 1996). En el caso de los agentes económicos, es relativamente sencillo. En cuanto al empresario, suponemos que maximiza beneficios o minimiza costes monetarios, $o$, cuando menos, intenta no tener pérdidas (de lo contrario desaparecería). En lo concerniente a los consumidores, es más dificil atribuirles preferencias, pues sólo sabemos lo que deciden en el mercado, no lo que van a realizar con los bienes adquiridos. Ahora bien, como recuerda Margolis (1982), no importa que conozcamos cuál es la utilidad concreta que reporta una mercancía, pues en la medida en que los productos están sujetos a precios que expresan relaciones marginales de sustitución, dichos precios son un buen indicador de la intensidad de preferencias del consumidor (esta es la base de la teoría microeconómica del consumidor). Fuera del mercado, no tenemos indicadores objetivos sobre las preferencias de los consumidores, pues no sabemos cuál es la relación marginal de sustitución entre sus 
distintas decisiones. Y no podemos emplear el criterio de la selección natural (como ocurre con las empresas) para suponer que consumidores, trabajadores u hogares desaparecen si no se comportan como si maximizasen (Conlisk, 1996). Por tanto, es necesario realizar un supuesto sobre la naturaleza de las preferencias. Para ello podemos acudir a una teoría sobre la formación de preferencias (tarea que los teóricos de la elección racional no consideran resuelta (por ejemplo, Opp (1998: 225)), o bien podemos realizar más supuestos sobre las mismas, como hace Becker.

Para Becker (1976a, 1977), se debe suponer que las preferencias son constantes ${ }^{7}$, tanto a lo largo del tiempo para un individuo como entre individuos en distintos lugares y momentos históricos. Estas preferencias no se refieren a mercancías adquiridas en el mercado, sino a los productos finales que produce cada hogar usando las mercancías y servicios adquiridos en el mercado. Por tanto, el hogar es considerado como una unidad más de producción, siendo así uno de los padres de la Nueva Economía del Hogar. Las preferencias se "refieren a aspectos fundamentales de la vida, tales como la salud, el prestigio, placeres sensuales, benevolencia o envidia, que no siempre mantienen una relación estable con el mercado de bienes y servicios" (Becker, 1976a: 5). Con este supuesto se limita el recurso a alegar cambios de preferencias cada vez que se observan cambios en el comportamiento, al tiempo que se pueden mejorar las predicciones estudiando los precios sombra de esas preferencias últimas en vez de estudiar sólo los precios de los bienes que hay en el mercado. Afirma que las preferencias en sí mismas no pueden ser explicadas por la economía, tarea que deja a otras ciencias sociales, pero confiando especialmente en la sociobiología ${ }^{8}$ (Becker, 1976b). Lo que sí puede hacer es suponer que los individuos mantienen constantes sus preferencias y explicar por qué varía el comportamiento. Esta estrategia desplaza el problema de la medición de las preferencias por el de la suposición de cuáles serán esas

\footnotetext{
${ }^{7}$ Considerando lo que vamos a ver sobre Becker, podemos entender la siguiente afirmación de Bunge (1999: 157) como una boutade, si no como una simple estupidez: "[suponen que la función de utilidad] es la misma para todas las personas, pero esto contradice el supuesto inicial según el cual las personas son individualizadas por sus preferencias" (Bunge 1999: 156-7). Como veremos, en una consideración beckeriana lo "individualizado" no son las preferencias, sino las restricciones. Pero la crítica es mucho más errada si tenemos en cuenta que en general (más allá de Becker) no es relevante para la teoría que cada agente tenga sus preferencias, sino simplemente que elija de forma consistente en función de esas preferencias, que además se espera que sean estables en el tiempo.

${ }^{8}$ Se refiere a la sociobiología de Wilson (1975), que puede interpretarse como "una aproximación económica" al estudio de los genes. Desde esta perspectiva, se aplican los principios de maximización sujeta a restricciones a los genes, cuyo fin es reproducirse a través de las generaciones de una especie. Parece que en Becker hay un claro interés por presentar las relaciones sociales como naturales, probablemente, en aras de un mayor parecido entre economía y ciencias naturales. Es decir, en presentar construcciones históricas limitadas por los recursos existentes como impuestas por principios naturales a los que no se puede escapar. Si antes el orden social era natural por ley divina, ahora es natural por las leyes de optimización.
} 
R I S

REVISTA INTERNACIONAL DE SOCIOLOGIA

№ 37, ENERO-ABRIL, 2004

JOSÉ SATURNINO MARTINEZ GARCÍA

preferencias "naturales". Esta línea de trabajo no ha sido desarrollada por Becker, pero sí ha tenido fuerza recientemente (Mundó y Raventós, 2000), y trabajos como el del psicólogo evolucionario Kanazawa (2001), que recurriendo a mecanismos psicológicos evolucionarios da cuenta de la formación de preferencias individuales y valores culturales, empleando explicaciones de tipo sociobiológicas. Pero como señala Kimmel (2000) en un contexto de debate general sobre las explicaciones de este tipo, éstas suelen adolecer de una selección sesgada de los ejemplos que toman para formar sus ideas, así como no resuelven bien el paso de explicaciones puramente teleológicas a explicaciones que puedan dar cuenta de cómo un proceso evolutivo pudo desembocar es determinadas configuraciones psicológicas, deficiencias que son subsanables, por no ser intrínsecas a este programa de investigación.

Dos son las condiciones necesarias para realizar el principio explicativo beckeriano. Una es suponer que todos los individuos maximizan su utilidad sujeta a restricciones en un contexto de mercado. Por ser más precisos y no perdernos en metonimias y confundirnos con el uso cotidiano de la palabra "mercado", diremos que Becker está pensando en un entorno paramétrico (el entorno le viene dado al agente y sobre él no puede influir) e interdependiente (nos podemos referir a las acciones individuales sin tener en cuenta los papeles que ocupan los agentes (Boudon, 1979: 94)) . La otra es ampliar el tipo de variables que integran la función de producción (Becker, 1971), considerando las variables de ambiente, las cuales dificultan o facilitan la producción del bien buscado, y las características individuales, que pasan a ser capital incorporado a los consumidores-productores. El clima es un buen ejemplo de variable de ambiente, ya que dependiendo de que sea más moderado o más extremo, ceteris paribus, puede modificar el precio de otros factores como la salud, o afectar al presupuesto, debido a los gastos necesarios para conseguir una temperatura agradable; de esta forma, el distinto uso del tiempo de ocio, al aire libre o en recintos cerrados en lugares de clima templado o frío, no manifiesta preferencias individuales o rasgos culturales, sino que las restricciones son distintas, supuestas las mismas preferencias por una temperatura confortable. La diferencia de gustos entre aquellos con alta y baja acumulación de capital humano, se explica porque su productividad para obtener determinados placeres es distinta. En un caso extremo, el placer que un libro puede reportar a un analfabeto no puede venir de su lectura; sin embargo, una persona habituada a leer puede sacarle mayor provecho. A parte del capital humano, Becker propone otras especies de capital, como el capital de consumo (Stigler y Becker, 1977) o el capital social (Becker, 1974).

Como vemos, para mantener constantes las preferencias proliferan conceptos de capital ad hoc, vacíos de significado, tal y como señala Ultee (1996) o que poco tienen que ver con lo que normalmente se entiende por capital. Como apunta Elster (1997), siempre es posible encontrar que algo se parece a algo, mediante un parecido superficial (como entre las alas de los pájaros y las alas de los mur- 
ciélagos), es posible establecer analogías, mientras que en ciencia, lo realmente relevante son las homologías, que permiten detectar una estructura común ante una apariencia distinta (como la que hay entre nuestras manos y las alas de los murciélagos). Sigue Elster caracterizando lo que realmente cabe entender como capital, definible por los tres rasgos siguientes (1997: 750): ser el resultado de acciones elegidas libremente (inversiones); cada inversión disminuye la utilidad presente en espera de incrementar la utilidad futura, y es reversible, en el sentido de que disminuye si no se mantiene (amortizable).

Con estos tres criterios analiza Elster distintos conceptos de capital para concluir que no se corresponden con la idea de capital, lo que nos parece acertado.

De lo visto en este apartado, debemos destacar las siguientes consideraciones:

- Los axiomas sobre las preferencias son supuestos, y como tales deben estar sujetos a revisión en la investigación.

- Entre estos axiomas debemos resaltar que se supone que las ordenaçiones se realizan sobre una única dimensión, que deben poseer en común los elementos de la comparación. Esta unidimensionalidad produce una lectura muy restrictiva de la realidad social.

- Es dificil encontrar un indicador de las preferencias que no esté relacionado con las elecciones, que es lo que la teoría debe explicar y predecir. Hay dos líneas principales para solucionar este problema: o se tiene una teoría sobre la formación de preferencias, o se hacen supuestos sobre las preferencias.

\section{VARIEDADES DE LA ELECCIÓN RACIONAL}

Una vez definido un "núcleo duro" de lo que podemos entender por elección racional, caben diversas posturas que podemos etiquetar con las siguientes denominaciones: instrumentalismo, reconstrucción formal, realismo, reconstrucción estadistica y reconstrucción racional. Son distintas, pues obedecen a estrategias diferentes a la hora de construir el objeto de investigación, ya que sus conceptualizaciones metodológicas y ontológicas no coinciden necesariamente. Pero tampoco son incompatibles, por lo cual resultan confundidas tanto por quienes están a favor como en contra de la elección racional. Con esta separación clara, los debates en torno a este programa de investigación serían más productivos, pues sabríamos si hablamos del mundo (la elección racional como ontología social) o de las ciencias sociales (como metodología), y en este caso, de qué tipo de ciencias sociales, con lo cual resulta más fácil comprobar la pertinencia de los argumentos en liza. A continuación se expone cada postura, señalando algunas posibles críticas. Además, introduciremos un nuevo concepto, el calculus, para que quede constancia de la diferencia entre el cálculo de la adecuación racional entre medios y fines como proceso consciente de los agentes, y el calculus como principio más general, que incluye tanto el cálculo consciente de los agentes como 
la elaboración teórica que reconstruye o supone racionalidad instrumental en las explicaciones, pero no en la mente de los agentes ni en el "mundo".

Como uno de los máximos exponentes del instrumentalismo tenemos a Friedman (1953), abanderado del pensamiento neoclásico, en su vertiente monetarista. Este autor lanza su propuesta dentro del debate metodológico de la economía. En tanto que la elección racional puede caracterizarse por la extensión de los métodos económicos a diversos objetos de investigación, es pertinente considerar su argumentación, máxime cuando se considera que la elección racional no es un "desembarco" de la economía en general, sino de la ortodoxia neoclásica en particular (Etzioni, 1991: 7, citado por Zafirovski, 1999; Zafirovski, 2000; Macy y Flache, 1995). Para Friedman, el supuesto de racionalidad instrumental no debe entenderse como un principio explicativo del funcionamiento real del mundo, sino más bien como un artefacto tecnológico que nos ayuda a organizar nuestra información y a predecir hechos. La clave para Friedman está en que los modelos, al menos en economía, no nos hablan del mundo, en el sentido de que no es necesario que las hipótesis sobre las que se construyen sean más o menos realistas, sino que nos ayudan a predecir lo que puede ocurrir porque las cosas suceden como si fuese cierto el modelo, independientemente de lo adecuado que el modelo sea a los hechos. La validez de la explicación queda limitada a la validez para predecir nuevos fenómenos, afirmando incluso la conveniencia de emplear supuestos no realistas. En un esfuerzo por ser comprensivo con esta boutade, enunciada al margen de los debates metodológicos sobre la ciencia, Blaug (1980: 140) la interpreta más bien como una reacción producto del hartazgo de los neoclásicos a las críticas recibidas desde otras doctrinas económicas, que durante un siglo no habían considerado los éxitos predictivos neoclásicos. Y explica su popularidad por algo que podríamos expresar como la complacencia metodológica con el trabajo de "científico normal" de los economistas. Pero a pesar de ser uno de los artículos metodológicos más leído entre los economistas, pocos son los metodólogos de la economía que lo defienden actualmente, a juicio de Hausman (1992: 163)

Metodológicamente, lo menos que cabe decir es que peca en exceso de sospechosa ingenuidad ${ }^{9}$. Son varias las cuestiones que esta argumentación obvia. Varios modelos pueden ser compatibles con las mismas predicciones, y la mejor garantía de que disponemos para que un mismo modelo sea coherente con distintas predicciones, según varían los datos, es que sean ciertos los

\footnotetext{
${ }^{9}$ Sospechosa, porque esta propuesta metodológica va acompañada de la defensa del programa de investigación neoclásico como sinónimo de economía positiva, y porque desde esta perspectiva de la economía positiva deducen propuestas ideológicas que fundamentan las políticas neoliberales, que intentan presentarse como soluciones técnicas y no politicas, precisamente por venir del núcleo de esta economía positiva.
} 
supuestos (Opp 1998: 222). Como expone Blaug (1980: 126-141), no está claro que puedan separarse tan fácilmente supuestos y predicciones en la formulación de un modelo explicativo, o que el contraste empírico de las predicciones vaya a ser más fácil que el de los supuestos. Además, el estudio sobre los supuestos no sólo mejora el desarrollo de la disciplina, también nos ayuda a corregir el modelo cuando las predicciones son erradas (Rosenberg, 1992). Confiar sólo en la predicción como único criterio de validez no nos previene de las relaciones espurias que haya en los datos. Y si tan importantes son las predicciones, habría que ser muy riguroso en la evaluación de las teorías a la luz de su éxito predictivo. La evidencia más bien parece corroborar que cuando los supuestos de competencia perfecta no se cumplen (agentes sin poder de mercado, información perfecta, ausencia de costes de transacción, de deliberación, de entrada y de salida del mercado), los resultados se pueden apartar de forma sistemática de los estados de equilibrio predichos (Conlisk, 1996: 683-4). Además, ni siquiera Friedman es del todo coherente consigo mismo, pues cuando critica los modelos de competencia monopolística no lo hace por el ajuste de sus predicciones (que son razonablemente buenas), sino por el realismo de sus supuestos. Todo esto sin tener en cuenta que a la ciencia también se le piden explicaciones, no sólo predicciones. Como señala McCloskey (1985), no nos sentimos satisfechos si se nos dice que un pájaro vuela como si supiese ingeniería aeronáutica, necesitamos saber cómo vuela realmente. Si se desea mejorar el conocimiento de los hechos y hablar de economía positiva en particular y de un modelo explicativo de las ciencias sociales en general, habrá que revisar los supuestos según la evidencia disponible. Si se propone la competencia perfecta como modelo de organización social, entonces estaremos hablando de economía política y de problemas normativos.

Debido a esto último hay quienes sostienen que la elección racional es una reconstrucción formal de la acción social. Esta reconstrucción formal es una herramienta vacía de contenidos sustantivos, es decir, sin supuestos sobre el funcionamiento del mundo social, por lo que se entiende a la elección racional como una especie de gramática de las ciencias sociales, compatible con diversos teorías ${ }^{10}$ (Aguiar y de Francisco, 1999; Hirschleifer, 1985). Así entendida, la elección racional puede ser una herramienta para orientar la toma de decisiones, como proponen Habermas (1982: 29-30), en el contexto general de las ciencias sociales empírico-analíticas u otros, como

\footnotetext{
${ }^{10}$ Grignon (1998) nos parece contradictorio, pues por un lado reconoce las virtudes de los modelos matemáticos como control epistemológico, pero por otro critica que los modelos formales cuando se despojan de los supuestos del homo economicus se convierte en modelos vacíos. Pero precisamente es este vacío lo que hace que podamos considerar a la elección racional como una gramática de las ciencias sociales.
} 
Rosenberg ${ }^{11}$ (1992) y Aguiar (1993). Para estos autores, en tanto que los supuestos no se cumplen (los individuos empíricos no se comportan como supone la teoría más sustantiva), este marco teórico es relevante debido a que proporciona un aparato analítico útil para la toma de decisiones por parte de agentes políticos y económicos, o un lenguaje formal práctico para la reflexión teórica. Esta utilidad deriva de que la teoría permite tomar decisiones eficientes, una vez fijados los recursos disponibles y los objetivos a cumplir. Pero Bunge (1999: 166) —cuyas críticas veremos con más detalle más adelante - niega esta posibilidad, pues considera que la teoría es tan pobre en su descripción del mundo que no es útil ni siquiera para reflexionar sobre cuestiones normativas.

En cuanto a quienes defienden el realismo, lo primero que cabe decir es que resulta preferible no cometer la maldad de catalogar a nadie de realista en el sentido más estricto, es decir, considerar que realmente los agentes deciden la mayor parte del tiempo de forma totalmente racional, pues un sencillo ejemplo de introspección nos lleva a pensar que esto no puede ser muy cierto, pues actuamos muchas veces por la costumbre, movidos por el grupo de referencia o pertenencia, guiados por valores morales, de forma más o menos compulsiva, no hacemos lo que pensamos que deberíamos hacer, debido a la debilidad de nuestra voluntad o tomamos decisiones donde no podemos aplicar criterios optimizadores, pues no disponemos de información clara ni de nuestras preferencias, ni de nuestros recursos, ni de las probabilidades de éxito de nuestras acciones, etc., (¿se imagina el lector que exista una pareja - no aquejada de una patológica hiperracionalidad-que razone el número de sus coitos como lo hace Becker? (1981: 136-7)). Por ello, los realistas intentan encontrar explicaciones que permitan un salto "natural" entre la optimización sobre el papel y las acciones más frecuentemente observadas que puedan apartarse de este modelo teórico. Hablamos de salto natural debido a que suele atribuirse a ciertos rasgos de la naturaleza humana y sus limitaciones cognitivas o a la imposibilidad de lograr ciertos fines mediante acciones instrumentales, como los subproductos. Elster señala la imposibilidad de la elección racional en ciertas situaciones por dos vías: la indeterminación de las predicciones, o la falta de adecuación explicativa de este programa de investigación (Elster, 1989b: 16-32).

\footnotetext{
"En esta línea de presentación de la economía como ajena a la ciencia, Rosenberg también da otra posibilidad: la economía (y por extensión la elección racional) es una rama de las matemáticas, que sigue su desarrollo independientemente del "mundo", de la misma forma que la geometría euclídea parte de unos supuestos que se desarrollan independientemente del mundo, y una variación de esos supuestos no altera la disciplina, simplemente produce nuevas geometrías. Luego serán otros científicos, no los matemáticos, quienes se decanten por una geometría o por otra, en función de que los supuestos reflejen mejor la realidad que pretenden investigar.
} 
El problema de la indeterminación se origina cuando hay varios óptimos posibles, con lo cual la teoría produce predicciones incompatibles simultáneamente, o puede que no exista el óptimo. En teoría de juegos este resultado suele ser habitual, así como en entornos de incertidumbre. También plantea problemas la acumulación de información necesaria antes de tomar la decisión. En estos casos la teoría es pobre en cuanto a predicciones precisas, pero no es errónea.

La falta de adecuación se produce en aquellos casos en los que la teoría sí es errónea. Elster previene en contra de la hiperracionalidad: intentar explicar todo de acuerdo con el principio de racionalidad. Hay situaciones donde este principio falla (Elster, 1983 y 1984). Por ejemplo, en las situaciones de acrasia (debilidad de la voluntad): nos ponemos objetivos que no cumplimos debido a que caemos en "tentaciones", como ver la "tele" en vez de estudiar, cuando resulta mucho más preferido aprobar la asignatura que continuar viendo insulsa programación televisiva. Otras situaciones de este tipo son aquellas en que los fines de la acción son subproductos, es decir, estados que sólo se obtienen si no se les persigue deliberadamente, como dejar de pensar en algo, alcanzar la fe en aquello que no se cree o conseguir impresionar a otras personas (y no ser percibido como un "fantasma"). Considera Elster (1989b: 38) que, de las distintas explicaciones para dar cuenta de la irracionalidad, probablemente el recurso a las normas sociales sea el más prometedor, y a ello dedica parte de su trabajo posterior (Elster, 1991) ${ }^{12}$.

Boudon (1996, 1998a, 1998b, 1999, 2003; Lizón, 2000), considera que estos problemas de la elección racional son debidos a excesivos supuestos sobre la conducta humana, y que es posible limitarlos al individualismo, que las acciones humanas por principio son comprensibles y que son producto de la racionalidad, pudiendo dejar de lado los supuestos sobre el reduccionismo de toda racionalidad a racionalidad instrumental, el egoísmo o la maximización, pues considera que estos tres últimos son los que llevan a la elección racional a no poder explicar ciertos fenómenos. La propuesta de Boudon es el modelo cognitivista, en el que los agentes guían sus elecciones por razones "cognitivas", que se deben a un conocimiento con un fundamento incierto (que puede implicar ideas erróneas sobre el mundo). Estas razones son creencias no intencionales y creencias normativas, es

\footnotetext{
${ }^{12}$ Aquí no vamos a entrar a debatir la cuestión de las normas desde la perspectiva de Elster pues sería salirse del objeto de este trabajo. Pero sí nos gustaría señalar que quizá esta solución no sea ni tan novedosa ni tan prometedora. No es novedosa en tanto que el estatuto teórico de las normas en los modelos explicativos pasa a ser similar al del conjunto de oportunidades: las normas son un tipo nuevo de restricción a la acción. Y no es prometedora en la medida en que lo único que consigue es trasladar el problema a la génesis de las normas. El propio Coleman (1990) reconoce la insuficiencia de la elección racional para explicar el origen de normas sociales que no sean regulaciones convencionales, como las normas de tráfico. Hollis también plantea la dificultad con que se encuentra la elección racional para dar cuenta de las preferencias y las normas (Hollis, 1994: 121).
} 
decir, enunciados sobre cómo es el mundo o cómo hay que comportarse en él, sin que sean necesariamente ciertos, aunque si lo sean para los agentes, y parte de la labor explicativa es encontrar los motivos por los que a los agentes les resultan verdaderas estas razones falsas.

Otra línea de trabajo es la de los marcos (frames) de interpretación de las pérdidas, los costes y los beneficios de la acción o los sesgos cognitivos (Kahneman y Tversky, 1982; 1984; Santamaría, 1995) ${ }^{13}$. De ser cierto que el razonamiento humano incluye sesgos cognitivos, que llevan a inferencias sobre el mundo erróneas, señala una debilidad en el "individuo racional y estadístico" al que se refieren Blossfeld o Goldthorpe, y que veremos más adelante, pues las desviaciones sobre las decisiones racionales pueden ser sistemáticas. Conlisk (1996) revisa estos problemas, y como apoyo a la argumentación realista, tenemos que bajo ciertas circunstancias un razonamiento erróneo por parte de los consumidores en un mercado puede alterar su equilibrio (Russell y Thaler, 1985, citados por Rabin, 1998), o una pequeña proporción de agentes de racionalidad limitada en un mercado pueden influir más que proporcionalmente sobre el equilibrio de mercado debido a efectos de "congestión" (Rabin, 1998).

Algunas críticas al realismo se deben a la importancia que da a la racionalidad instrumental como principio explicativo, pues se afirma que es una proyección etnocéntrica. Pero no está claro qué es más etnocéntrico, si proyectar o negar, es decir, si pensar que toda la humanidad a lo largo de su historia se ha caracterizado por tomar decisiones según la racionalidad instrumental o si la elección racional es un fenómeno estrictamente moderno y occidental, circunscrito a agentes inmersos en formaciones sociales dominadas por el modo de producción capitalista: ¿ somos unos más homo sapiens que otros? ${ }^{14}$

Para dilucidar esta cuestión conviene recurrir a la antropología, pues en tanto que aporta materiales sobre diversas culturas puede aclarar algo sobre esta posible universalidad del hombre. Vemos que una polémica como la que hay entre elección racional y otras corrientes de la sociología es similar a la polémica entre

\footnotetext{
${ }^{13}$ Hay que señalar que el modelo cognitivista de Boudon se opone a la existencia de marcos, que considera "cajas negras", es decir, explicaciones que ni son causales ni son conscientes para los agentes, y que suelen referirse a conceptos difíciles de observar.

${ }^{14}$ Hollis (1994: 253-256) reflexiona a partir del estudio de Evans-Pritchard (1937) sobre los azande y su brujería, para concluir "Racionalmente hablando, los azande son como nosotros en su intento de predecir y controlar su mundo. Razonan partiendo de premisas hacia conclusiones, tal como hacemos nosotros, con el mismo respeto por el experimento y el método científico. En contraste con ello, sus nociones místicas son particulares y amenazan hurtar la lógica objetiva, por ejemplo, bloqueando el pensamiento crítico en lo que respecta a la evidencia empirica [...] ¿Qué creencias sobre el mundo tienen los azande? [...] La respuesta sería que resulta que los azande comparten nuestra idea de racionalidad, pero la adaptan al contexto local". Contexto local, que podemos interpretar como racionalidad sustantiva, concepto éste que veremos con más detalle al referirnos a Godelier.
} 
formalistas y sustancialistas entre los antropólogos ${ }^{15}$. Como bien señala Martínez Veiga (1990: 49-50) este debate se debe básicamente a una confusión: "[los formalistas] no comprendían que en muchos momentos no estaban haciendo una descripción de un fenómeno empírico sino construyendo un modelo, mientras que [los sustancialistas] se empeñaban en abandonar totalmente el modelo y basarse únicamente en lo que ellos consideraban la realidad empírica". La solución (o mejor, a disolución) de esta polémica, como también señala este autor, la podemos encontrar en Godelier. Básicamente, el mérito de Godelier (1966) se encuentra en su distinción entre una racionalidad intencional y otra no intencional. La racionalidad intencional podemos asimilarla a una visión de la elección racional, en tanto que se refiere a cómo los agentes actúan en función de sus medios y de sus fines, de una forma razonable. La racionalidad no intencional da contenido sustantivo a esta racionalidad vacía, es la lógica del modo de producción o sistema social (o como se prefiera) en la que los individuos están "incrustados" (embednếss, en la tradición anglosajona).

Por ejemplo, Godelier (1984: 63-65) recurre al caso de tramperos blancos e indios en la península de Labrador, entre otros. Ambos se hallan en el mismo contexto ecológico con las mismas técnicas para lograr los mismos fines, pieles preciosas. Sin embargo, la racionalidad económica de ambos grupos es distinta: el trampero blanco maximiza beneficios monetarios, mientras que el indio optimiza tanto el dinero como el mantenimiento de las relaciones con su familia, no ya por afecto ni por respeto al medio ambiente, sino porque se concibe a sí mismo como miembro de un clan que maneja criterios no mercantiles en sus tareas productivas (como el honor), y no como un individuo que compite en un mercado impersonal con una vida familiar independiente de ese mercado. No cabe hablar de irracionalidad en ninguno de los dos. Cada uno reproduce una racionalidad económica adaptada no sólo al medio físico (idéntico para ambos), sino también adaptada al medio social, que, en buena parte, estas racionalidades económicas contribuyen a reproducir.

Otro matiz de la elección racional lo podemos encontrar en quienes la ven como un desarrollo de la sociología comprensiva weberiana, en la que el actor racional es un tipo ideal (ni un instrumento predictivo, ni un sujeto empirico) que nos permite comprender y explicar las acciones sociales (por ejemplo Abell, 1996) o con matices, Hollis (1994) o Norkus (2000)), aunque hay quienes disienten de

\footnotetext{
${ }^{15}$ En la exposición confusa y sesgada de Zafirovski (1999) de la elección racional hay que destacar como uno de sus más grandes errores la lectura partidista que hace de la antropología, basándose principalmente en Polanyi y Sahlins, ambos sustancialistas. Por supuesto, Zafirovski no tiene en cuenta la disolución de esta polémica con los argumentos que aquí estamos expresando.
} 
esta posibilidad, como Alonso y Callejo ${ }^{16}$ (1994:120-1)). Desde esta perspectiva, la elección racional es una reconstrucción racional del sentido de la acción social, es una herramienta en la búsqueda de marcos que permitan encontrar el significado que tiene para los agentes. La sociología debe proporcionar una comprensión empática de la acción social, con el fin de obtener una explicación causal de su curso y sus efectos, pues si falta el conocimiento del sentido que relaciona dos hechos estamos "ante una probabilidad estadística no susceptible de comprensión" (Weber, 1922: 11). La comprensión empática se logra adaptando el modelo "más simple posible" (más parsimonioso) de elección racional individual; la acción social se interpreta con el "modelo más simple posible" de acciones interdependientes (interacciones) de los individuos; y las explicaciones causales se establecen aclarando las relaciones macro-micro-micro-macro a las que hacíamos referencia anteriormente. Suponiendo que toda acción es racional con arreglo a fines, estos tres principios weberianos se cumplen en el paradigma de elección racional.

Pero para Weber, además de la acción instrumental, existen los siguientes tipos de acciones: axiológica (con arreglo a valores), tradicional y afectiva. Por motivos explicativos debemos reconstruir toda acción como racional con arreglo a fines: cómo hubiesen actuado los protagonistas de disponer de toda la información relevante y sobre este tipo ideal, reconocer las desviaciones de la racionalidad, desviaciones que deben explicarse causalmente. Por contraste con la acción instrumental así reconstruida, conoceremos lo realmente sucedido (Weber, 1922: 7,18 ). Desde esta perspectiva no es exagerado considerar que las teorías de la elección racional son una forma posible de entender la sociología comprensiva de Weber, aunque como señalan Farinetti (1998) o Norkus (2000) Weber no intenta en ningún momento reducir toda acción a elección racional instrumental, pues reconoce los otros tipos de acción. Según Hedström y Swedberg (1998: 79), esta lectura weberiana de la elección racional se debe a que no se trata de comprender la acción de un actor concreto, lo que normalmente produce historias sobre casos - más cercanas a las anécdotas - antes que explicaciones, sino que se intenta construir teóricamente un actor hipotético y atribuirle intenciones, de forma que se parezca al que existe realmente. Este procedimiento permite una mayor generalidad de la explicación, así como mantiene los principios de una sociología comprensiva, pues es necesario identificar los motivos, intenciones

\footnotetext{
${ }^{16} \mathrm{~A}$ juzgar por sus argumentos, estos autores parecen negar que haya relación entre la postura instrumentalista y la metodología weberiana, punto en el que estamos de acuerdo. Pero en esta crítica incluyen a Elster, que precisamente se caracteriza por el estudio de la inadecuación e indeterminación de la elección racional y por incluir como un elemento más de la explicación las normas sociales. Por otra parte, tal como aclaramos en este párrafo, sí es posible considerar la elección racional como un desarrollo de la sociología comprensiva.
} 
y recursos que el actor percibe como disponibles para poder dar cuenta de sus acciones como si fuesen racionales, en el seno de una estructura causal. Un como $s i$ reconstructivo e inductivo en vez de deductivo (como en Friedman).

A Blossfeld y a Goldthorpe los podemos situar en otra postura: la reconstrucción estadistica. La elección racional es una forma de aproximarse al tipo medio del comportamiento de un agregado de individuos. Acabamos de mencionar que para Weber una correlación sin un mecanismo explicativo es una descripción de un fenómeno, no una explicación. Y un mecanismo causal que no se apoye en evidencia empírica no dice nada acerca de su pertinencia para explicar hechos socialmente relevantes (Weber, 1922: 11). Por ello, Blossfeld (1996) afirma que la ventaja de la elección racional estriba en que propone una serie de mecanismos causales sencillos, como los que aquí hemos visto considerar que existen restricciones a la acción, que las preferencias de los actores son consistentes (no contradictorias) y que son capaces de crear expectativas racionales sobre acontecimientos futuros a partir de la información disponible y de sus experiencias pasadas (estos dos últimos supuestos no son tan fundamentales como el primero). Para Goldthorpe (1998b), una teoría determinista de la acción, como la elección racional, no puede explicar todos los datos de grandes encuestas, en las que los ajustes estadísticos suelen ser bajos (esto es, hay muchos individuos que no se comportan según predice el modelo estimado, basado a su vez en un modelo de elección racional). Pero sí puede dar cuenta del comportamiento de un individuo teórico resultado del agregado de todos los individuos. Esto se debe a que las influencias que son puramente individuales son aleatorias y se anulan unas con otras, por lo que no hace falta suponer que todos los individuos se comportan de forma racional, sino que, dadas las circunstancias, el agregado tiende a comportarse racionalmente (argumentos que toma de Hernes (1992:427) y Stinchcombe (1968), y que nos parecen muy parecidos a los empleados por Becker en una de sus exposiciones sobre la ley de la demanda, como hemos visto).

Estos autores parecen olvidar que las desviaciones del patrón racional también pueden ser sistemáticas, debidas a problemas cognitivos (como recoge el modelo cognitivista de Boudon), y llegar a estados distintos de los que cabe esperar en una situación de equilibrio entre agentes racionales que no adolezcan de dichos sesgos, como ya hemos señalado. Por otro lado, como critica Edling (2000) a Goldthorpe, el que dispongamos de una narración coherente con los datos, no quiere decir que los resultados estadísticos estén explicados, y aún menos que dicha narración sea necesariamente cierta; además, sigue señalando Edling, otros modelos explicativos también pueden ser probabilísticos. Esta crítica está emparentada con la que hemos visto que hace Blaug (1980) al instrumentalismo, pues en ambos casos cada explanans es una narración que se ajusta a los datos, pero eso no quiere decir que los expliquen. También debemos añadir las críticas de Lindenberg (1996) a Goldthorpe: la simplificación del explanandum para que pueda ser operacionalizable con los datos recogidos mediante cuestionarios puede 


\section{RIS}

ser excesiva, y se debe hacer más hincapié en la perspectiva del sujeto, atendiendo a factores tales como el framing, y no sólo en posibles elecciones racionales.

Visto esto, queda más clara la idea de calculus que avanzamos previamente. $E l$ calculus es la herramienta teórica fundamental de todas las visiones no realistas de la elección racional, más general que el cálculo, que sería el proceso real mediante el cual los agentes establecen las relaciones entre medios y fines. El calculus puede ser tanto un proceso real de agentes conscientes, como una reconstrucción (instrumentalista, formalista, comprensiva ${ }^{17}$ o estadística) de comportamientos observados. Aclarar las distintas posturas que argumentan a favor de la elección racional, así como distinguir entre calculus como instrumento teórico y cálculo como experiencia real esperamos que ayudará mucho a mejorar la calidad del debate en torno a la elección racional.

Estas perspectivas de la elección racional es posible agruparlas en tres, dependiendo de dónde sitúen la racionalidad: en la mente del investigador (instrumentalismo, reconstrucción formal), en los agentes (realismo, reconstrucción racional) o es un resultado del funcionamiento de la sociedad (reconstrucción estadística), no necesariamente consciente para los agentes.

\section{CRÍTICAS INFUNDADAS}

En principio, los supuestos de esta teoría, incluso su propia denominación, resultan tan contradictorios con otras corrientes de pensamiento, e incluso con la propia introspección, al tiempo que son aparentemente tan fáciles de entender, que son múltiples las críticas que se le hacen "desde fuera", sin entrar en los diferentes matices que hemos ido presentado. Estas críticas suelen referirse a "hombres de paja", producidos mezclando las distintas posturas de las que hablamos en un principio, especialmente la realista con la instrumentalista, pues no se puede criticar a los instrumentalistas por falta de realismo (ya que no es esa su intención), sino que habrá que criticarlos por sus malas predicciones. Y no se puede acusar a los realistas de producir "tontos racionales" (Sen, 1977), pues buscan en la sociología, y especialmente en la psicología (curiosamente no en la antropología) soluciones a la falta de racionalidad.

Heath (1976: 75-79) señala una serie de críticas falaces a la elección racional. Entre éstas, la afirmación de que es necesario recoger información antes de tomar una decisión, y como nunca podemos estar absolutamente seguros de disponer de toda la información para tomar la decisión, se encarecería tanto la toma de la

\footnotetext{
${ }^{17}$ Una reconstrucción comprensiva, si está bien hecha, sería una explicación realista, pues daria cuenta de por qué la acción ha resultado ser racional desde la perspectiva del agente.
} 
misma que al final no habría decisión. Pero esto sólo es necesario cuando existe un grado considerable de incertidumbre, en cuyo caso deben contabilizarse los costes de conseguir esta información. Cuando se va al mercado y se compra una barra de pan, no se toma en consideración la necesidad de acumular gran información sobre las cualidades de ese pan, pues es un producto más o menos estándar y el coste de una decisión errónea no sería considerable. Sin embargo, si lo que se desea es comprar un piso, normalmente se hace un mayor acopio de información, pero tampoco de forma infinita, sino hasta que se encuentra un punto en el que resulta razonable suponer que más información adicional no mejorará la compra.

Otra crítica falaz afirma que una decisión rápida es irracional, pero esto no es cierto cuando la utilidad entre dos decisiones es muy distinta: piénsese el tiempo que puede tardar un alumno en decidir si quiere que se le apruebe o se le suspenda una asignatura. También se cuestiona que las decisiones racionales deban ser conscientes, lo cual sólo es cierto en ciertas explicaciones realistas. Por último, pero no menos importante, hay quienes consideran que solo pueden explicar conductas egoístas, guiadas por el interés propio (por ejemplo, England y Kilbourne, 1990). También es falso, pues la teoría habla de adecuación entre medios y fines, pero no que los fines sean necesariamente productos del propio interés. Por ejemplo, el fin puede ser el altruismo, cuestión que trata Becker (1976b). En este caso, el fin buscado es el bienestar de los demás. Recordamos que la elección racional es posible entenderla como un modelo formal para guiar la explicación, no necesariamente una teoría sustantiva que agota todas las explicaciones posibles afirmando que todos somos egoístas miopes, como se la caricaturiza a veces. Cuestión distinta es la consideración del propio interés como más relevante desde la perspectiva teórica, pues sin la consideración por el propio interés, no podría existir el altruismo (Elster, 1989a); el altruismo existe debido a que la persona que recibirá el beneficio de la acción se comporta como egoísta. England (1993), desde una perspectiva feminista, cuestiona el que se aplique un modelo de comportamiento egoísta para explicar lo que ocurre en el espacio público (el mercado, la política), mientras que se aplica otro altruista para explicar lo que sucede en el espacio privado (la familia), contribuyendo de esta forma a reificar desde la teoría social el papel dominado de la mujer. Pero esto tiene más que ver con la teoría sustantiva de la familia de algunos autores, como Becker, que con las posibilidades de la elección racional, pues si en vez de optar, como hace dicho autor, por un modelo paramétrico para explicar el comportamiento de la familia, se opta por un modelo estratégico, se puede llegar a una teoría de la familia distinta, que tenga en cuenta las diferencias de preferencias y recursos en el seno de la familia (Behrman, Pollak y Taubman, 1995), y estudiar los problemas de la discriminación de género (Ishida, 2003).

Además de las equivocadas críticas citadas, que podemos catalogar como de "tradicionales", pues forman parte del "folclor" de la teoría social, hemos detectado 
otras críticas más recientes, también equivocadas. En este punto debemos detenernos en Zafirovski (1999), cuando habla de la incompatibilidad entre objetivos perseguidos por los agentes, pues ve como incompatibles los fines monetarios con respecto a otros más sociales, como el estatus. Precisamente lo que permite Becker (1981) mediante el recurso a los bienes realmente consumidos en el hogar $(Z)$, que son una transformación de los adquiridos en el mercado $(X)$, y a los costes de oportunidad, es averiguar en qué medida se está dispuesto a intercambiar entre los bienes generales (salud, estatus, confort...), no a que sólo se maximicen algunos. Posiblemente el fondo de esta crítica se refiera a lo expuesto cuando analizamos los supuestos sobre las preferencias: no está claro el criterio de comparación, es decir, necesariamente no hay una única dimensión en la comparación entre estados. Tampoco entendemos su crítica a una elección racional univariada, pues en el análisis más pedestre de los que se hacen actualmente pueden encontrarse varias variables. Suponemos que se refiere a que toma variables relacionadas sólo con conceptos monetarios, pero en este caso sería más apropiado hablar de unidimensionalidad, insistiendo en que hay que incluir varias variables en el análisis. Esto es algo que, en general, nadie niega, pues se pueden incluir múltiples variables, arguyendo bien que son proxies, bien que reflejan los costes de oportunidad o los beneficios esperados (la edad por ejemplo no es una variable monetaria, pero refleja el periodo aproximado de amortización de una inversión en capital humano).

En Searle (1995: 150) también encontramos otra crítica reciente y errada. Este autor propone un experimento mental: dada una lotería en la que se incluya la propia muerte en caso de perder - con muy baja probabilidad - junto con una recompensa económica — con muy alta probabilidad—, nadie jugaría, mucho menos si se incluye la muerte de un hijo. Esto contradice, según este autor, la teoría de la elección racional, pero parece no darse cuenta de que también contradice la existencia de seguros de vida... El riesgo de muerte cero no existe en ninguna actividad (podemos entender la vida como cierta probabilidad de estar muerto en el momento siguiente) y, además, realizamos voluntariamente actividades que incrementan nuestra probabilidad de muerte (gracias a lo cual Becker es capaz de elaborar una economía del suicidio). Quizá, si a cualquier padre le decimos que compre un boleto de una lotería con un premio multimillonario y con probabilidad de éxito muy próxima a la certeza de que su hijo siga vivo, y la muerte de su hijo con probabilidad infinitesimal (por ejemplo, 0,99999999 y 0,00000001 ' respectivamente) no compre el boleto, pues el dilema le parece inmoral. En este caso las preferencias entre el dinero y la vida de su hijo serían de tipo lexicográfico, lo cual supondría un caso particular de la teoría, antes que un fallo. Pero, por otro lado, no conozco ningún padre que decida no montar a su hijo en coche debido a que incrementa sus probabilidades de morir frente a ir caminando a cierta distancia. En esta otra situación, el padre toma una lotería que incluye el beneficio esperado de ir en coche junto con un incremento de probabilidad de la muerte de su hijo ${ }^{18}$. Puede que el mismo padre, que en el primer ejemplo manifiesta prefe- 
rencias lexicográficas entre el dinero y la vida de su hijo, manifieste preferencias "arquimédicas" en este caso, las diferencias entre ambos dilemas (formalmente iguales) sólo cabe atribuirlas a cuestiones expresivas. No es lo mismo afirmar que la muerte de un hijo puede ser resultado de un acto deliberado que de un imprevisto, la elección probablemente no es comparable en costes síquicos. Por otro lado, intuimos que en la crítica de Searle subyace un argumento razonable, aunque, como acabamos de ver, lo ilustra de forma no muy convincente. El argumento que subyace es el supuesto de que en toda comparación hay al menos una propiedad común a partir de la cual podemos ordenar nuestras preferencias, tal y como vimos cuando hablamós de la "completitud" de las preferencias, en el apartado 3. En el mercado esa propiedad es el dinero, pero fuera del mercado no encontramos ningún equivalente universal tan claro (lo más parecido sería el tiempo), y por tanto, la crítica es correcta en estas situaciones.

Bunge (1999) sorprende por el tono agrio de sus críticas, muchas de las cuales no tienen fundamento. Ya mencionamos algunas de esas críticas infundadas, veamos otras. Tacha de conservadora a la teoría, pues considera que no puede emplearse para hacer reformas sociales (p.165), cuando se puede aplicar perfectamente a estrategias políticas de izquierdas, como intentan hacer los marxistas analíticos (Carling, 1986; Roemer, 1986). La acusa de no servir para el estudio de los movimientos sociales, cuando Elster (1985) entre otros, empleando los desarrollos teóricos de Schelling (1977), ha probado que puede ser útil para el estudio de los mismos. Le niega toda evidencia empírica, cuando parece sensato considerar que algo de valor tendrán las múltiples investigaciones de economía, ciencia política o sociología ${ }^{19}$. Otras críticas que hace entran ya en el grupo que nos parecen más acertadas, como la imposibilidad de reducir las explicaciones a simples agregados de individuos.

\section{CRÍTICAS FUNDADAS}

Pasemos pues a una revisión de distintos autores que realizan estas críticas que consideramos más fundadas. Las podemos sintetizar en dos: no es posible reducir las explicaciones sociológicas a fenómenos puramente individuales y la teoría se encuentra con problemas para incorporar el sentido de las prácticas sociales.

\footnotetext{
${ }^{18}$ Argumento tomado de una comunicación verbal de Alberto Penadés.

${ }^{19}$ Tanto sectarismo y falta de elemental rigor sólo cabe entenderlo por algún tipo de obcecación, que intuimos a qué puede deberse: al exceso de pretensiones científicas de muchos teóricos de la elección racional (que McCloskey ha caricaturizado como "wannabe" -"queremos ser" como los científicos "de verdad"- al referirse a los economistas), que no está respaldado por la fuerza de los resultados, no tan contundentes como en las ciencias naturales.
} 


\section{RIS}

La primera de las críticas la encontramos expresada en Levine, Sober y Wright (1986), Mouzelis (1995), o en los ya citados Searle (1995), Bunge (1999), England y Kilbourne (1990); England (1993) o Godelier $(1969,1984)$. La segunda está en la obra de Bourdieu, pero no la hemos encontrado tan clara como aquí se expone, dado que se presenta en el contexto más general de los debates en torno al positivismo en ciencias sociales promovidos por Habermas (1982).

Para Searle (1995: 41-44) es falso el dilema que sólo permite elegir entre el reduccionismo a los individuos o la presencia de una especie de "supermente" externa a los individuos, una especie de ente hegeliano. Considera que al igual que existe intencionalidad individual, existe intencionalidad colectiva, pues no podemos reducir toda nuestra vida mental a estados explicables por un pronombre singular: "yo". De ser así, solucionaríamos la paradoja siguiente: para coordinar mi acción con otra persona, pienso lo que ella piensa, y ella piensa lo que yo pienso, como yo pienso que ella piensa lo que yo pienso... lo cual lleva a una regrěsión infinita. Esta paradoja se disuelve si consideramos que ambas personas se coordinan porque se piensan mutuamente como un "nosotros", no porque estén de acuerdo en todo, sino que para poder llegar a un desacuerdo hace falta un mínimo acuerdo compartido. Los hechos sociales son aquellos en los que entra en juego esta intencionalidad colectiva. Dicha intencionalidad colectiva queda explicada por ser un hecho biológico primitivo, que permite coordinar las acciones de los animales grupales ${ }^{20}$. Con lenguaje diferente, la crítica feminista (England y Kilbourne 1990; England 1993) viene a expresar una objeción parecida, pues resalta la importancia de tener en cuenta desde una perspectiva teórica que la sociedad no está formada por "yoes-escindidos" (separative-self).

La argumentación de Levine, Sober y Wright (1986) se construye a partir del debate en filosofía de la ciencia entre tipos y muestras. Las muestras son ejemplos concretos, como una huelga; los tipos son características que las muestras pueden tener en común. Así, una huelga puede ser subsumida en distintos tipos posibles: huelgas, luchas de clases, conflictos sociales... La ciencia intenta construir tipos (modelos teóricos) y relacionarlos con las muestras (evidencia empírica). El individualismo metodológico opera mediante el reduccionismo de las muestras y de los tipos a nivel individual. El problema estriba en que es posible reducir todas las muestras a muestras individuales (da igual que sean individuos empí-

\footnotetext{
${ }^{20}$ Volvemos sobre la obra de ensayo y divulgación del neurólogo Oliver Sacks (1994). En el capítulo sobre autistas, una autista funcional afirma que cuando está en grupo tiene serias dificultades para coordinarse con lo que ocurre en el mismo, llegándole a dar la sensación de que los no autistas disfrutan de poderes telepáticos. Esto nos lleva a pensar que el individualismo metodológico construye unos tipos ideales de individuos más parecidos a los autistas que a las personas normalmente socializadas, pues para los autistas sólo existe el "yo", son incapaces de concebir el "nosotros", como ocurre con el individualismo metodológico.
} 
ricos, instituciones o actores colectivos), pero no los tipos. Si volvemos sobre Searle, diremos que sólo observamos individuos (muestras), pero no podemos decir que la intencionalidad colectiva (un tipo) es algo limitado a la suma de mentes individuales. Un ejemplo más práctico lo vimos cuando nos referimos a la ilustración que hace Godelier de la racionalidad sustantiva: cazadores en el mismo ecosistema y con los mismos medios (muestras individuales), pero que gestionan sus actividades con racionalidades sustantivas diferentes (tipos colectivos), cuya explicación o descripción es irreducible al simple agregado de tipos individuales, pues es necesario recurrir a la existencia de instituciones irreductibles a los individuos. La crítica de Mouzelis (1995) es similar, y de hecho, recurre a un ejemplo parecido, el de agricultores en distintos contextos históricos, con comportamientos tan diferentes que es difícil reducirlos a puro individualismo metodológico abstracto.

Bourdieu comenta en distintas partes de su obra la teoría de la elección racional (1979: 99; 1980a: 81-89; 1980b: 35; 1983: 55-56; 1994: 144-152; 2000: 258-268; Bourdieu y Wacquant, 1992: 24-26, 124-126, por ejemplo). Bourdieu criticaría a los realistas por lo mismo que los autores anteriores, por el excesivo reduccionismo del individualismo metodológico, así como su falta de atención a cuestiones históricas y antropológicas, reduccionismo que no puede dar cuenta de la formación de preferencias, de los intereses (en el sentido de illusio) presentes en cada espacio social (campo). Critica que consideren que aquello que no se puede explicar por el cálculo racional de los actores se debe a un fallo de éstos (como vimos en el modelo cognitivista de Boudon). Y del instrumentalismo diría que si tiene éxito, es precisamente porque reconstruye el habitus, de forma que los intereses que el teórico atribuye a los agentes permiten la explicación como si los intereses fuesen realmente ciertos. Considera que los modelos matemáticos empleados por esta corriente confunden, en expresión marxiana que tanto le gusta, "las cosas de la lógica con la lógica de las cosas", es decir, son modelos abstractos coherentes, lógicos, pero que nada dicen sobre realidades sociales, crítica en la que coincide con Grignon (1998). También realiza críticas que presenta como generales, cuando en realidad sólo son aplicables a ciertos autores, como Becker, que reduce todas las lógicas sociales a la lógica mercantil y todos los espacios sociales al mercado. Pero esto no es una crítica general a la elección racional, pues la forma en que se entienda la utilidad y la optimización puede ser más flexible y amplia que la perspectiva beckeriana (Goldthorpe, 1998a).

Podemos considerar a la elección racional como un tipo de ciencia social de tipo empírico-analítico, con pretensiones teoréticas, y como tal, son pertinentes las críticas de Habermas (1982) de que este tipo de orientaciones deja fuera del debate racional y científico las cuestiones relativas a los problemas de sentido propios de todas las formaciones sociales. Ya sea mediante la separación entre juicios de hecho y de valor - difícil de sostener una vez que se ha probado la construcción social de la percepción de los hechos-, ya sea por obviar los prerrequisitos 
actitudinales previos y necesarios a la existencia de una comunidad científica, este tipo de orientaciones se saltan los problemas hermenéuticos característicos del mundo social (o mejor dicho, del "mundo de vida"). Pero a diferencia de Habermas, consideramos que el camino más adecuado a seguir no está tanto en la dialéctica como en las técnicas de investigación cualitativas de las ciencias sociales, aunque dejamos el desarrollo de esta cuestión para mejor ocasión.

\section{CONCLUSIONES}

Hemos intentado dejar clara la abundancia de críticas infundadas a la elección racional, bien por confusión entre las distintas posturas (realista, formalista, instrumentalista, estadística, reconstructiva), bien por exceso de constructivismo social (como en el caso de la escasez). Hemos introducido una nueva expresión, calculus, para diferenciar en el debate que el cálculo que aplica la elección racional puede ser consciente para los agentes, en una línea más bien realista, pero también puede no serlo, como en el caso de las otras orientaciones.

Podemos concluir lo siguiente: la teoría de la elección racional, como programa de investigación unificador en las ciencias sociales tiene deficiencias "hacia atrás" y "hacia adelante". Hacia atrás (los fundamentos), pues si nos limitamos a los axiomas sobre la elección (vimos los problemas que supone la ordenación de preferencias para explicar hechos que no suceden en el mercado), así como al acto de fe en el individualismo metodológico, podemos dejar sin explicación diversos fenómenos sociales muy relevantes, aunque quizá no lo sean tanto para las investigaciones económicas. Coleman mismo reconoce la dificultad para dar cuenta del surgimiento de normas que no sean regulaciones convencionales. Y Elster toma las normas como algo dado, pues sabe de las limitaciones para explicarlas dentro de esta corriente.

Hacia adelante (estrategias explicativas), Elster señala las limitaciones y los peligros de la hiperracionalidad, pues un modelo estricto de elección racional no puede considerar los subproductos de la acción (para los que probablemente haya que recurrir a otras corrientes sociológicas) o la debilidad de la voluntad (en este caso, lo razonable sería recurrir a la sicología). Que la elección racional no pueda explicar un fenómeno no quiere decir que no se pueda explicar, como parecen afirmar a veces sus defensores. Uno de sus déficit más grandes es precisamente la falta de preocupación por el significado de las prácticas sociales, problema central de la sociología comprensiva de Max Weber, de la que algunos de sus teóricos se consideran herederos. Las prácticas sociales no sólo son intencionales, también son significativas, y aquí es donde las corrientes teóricas más preocupadas por estas cuestiones tienen algo que aportar.

También cabe afirmar que entre las virtudes de la elección racional tenemos consideraciones morales y de parsimonia explicativa. Parece una buena ética de 
la investigación (como señala Coleman (1990)) suponer que las personas son sensatas y que el objetivo de la investigación es descubrir su sensatez. En cuanto a la parsimonia explicativa, lo bueno de explicar un comportamiento diciendo que es racional está en que no necesitamos recurrir a nada más para dar cuenta de él. Pero claro, no debemos olvidar el párrafo precedente, en el que afirmábamos que esto no siempre es posible.

Como corolario de lo visto, afirmamos que conviene mantener una relación pragmática y escéptica con la elección racional. Pragmática, debido a la parsimonia explicativa ya expuesta, la sensatez de buscar microfundamentos a las explicaciones e intentar respetar el esquema macro-micro-micro-macro de Coleman, evitando caer en el recurso explicativo de las "cajas negras" (explicaciones que ni son causales ni son conscientes para los agentes). $Y$ porque es necesario olvidar los prejuicios para trabajar con un programa de investigación que comparte su núcleo duro con la economía neoclásica. Además, intenta dar un lenguaje, una gramática, unificada para las ciencias sociales. Ideas tan sencillas como los contextos de la acción, la escasez o las preferencias, pueden facilitar el debate entre explicaciones alternativas, así como resaltar el esfuerzo por emplear términos que sean tan denotativos como se pueda, que eviten equívocos, degenerando los debates sobre explicaciones en confusiones semánticas. Decimos escéptica porque entendemos que son innecesarios el compromiso con el individualismo metodológico y la búsqueda a toda costa de racionalidad instrumental en las prácticas 0 en problemas cognitivos o falta de racionalidad de los agentes.

La intención no es ser ecléctico con la elección racional y otros programas de investigación, sino más bien considerar, que hay que dar "al César lo que es del César", lo cual quiere decir que se debe delimitar cuál es el ámbito de validez de la teoría, en vez de rechazar o asumir en bloque un programa de investigación o practicar un oportunismo teórico irreflexivo, "saltando" sin criterio entre las distintas corrientes teóricas. Este es el planteamiento de Habermas (1982) al diferenciar los ámbitos de aplicación de las ciencias sociales con vocación teorética de los de vocación hermenéutica. La claridad analítica de la elección racional, así como su esfuerzo por establecer predicciones contrastables, facilitan enormemente la tarea de detectar sus límites y anomalías, lo que, en general, no se puede decir de la mayor parte del pensamiento sociológico.

Resumiendo, hemos apuntado que algunos supuestos de la elección racional son bastante sensatos, como el de escasez, y otros más problemáticos, como los relacionados con las preferencias. En cuanto al individualismo metodológico, es un buen comienzo para abordar la investigación, pero cuesta considerar que tenga la última palabra. Su mayor virtud es apuntar la necesidad de microfundamentos de las explicaciones con conceptos sencillos. Pero es insuficiente para dar cuenta de relaciones institucionales, como señalan Levine, Sober y Wright e ilustrábamos con el trabajo de Godelier. La elección racional, entendida como un posible desarrollo weberiano (esto es, una reconstrucción racional de la acción) 
RIS

REVISTA INTERNACIONAL DE SOCIOLOCIA

№37, ENERO-ABRIL, 2004

JOSÉ SATURNINO MARTINEZ GARCí

puede funcionar adecuadamente en entornos de interdependencia y certidumbre, y con ciertos reparos, en otros ámbitos donde la teoría es indeterminada, como en situaciones estratégicas.

Su mayor fallo es la dificultad para percibir lógicas sociales, racionalidades sustantivas, estudiar el sentido de las prácticas sociales. Esto se manifiesta en el seno de este programa de investigación como problemas de la determinación de las preferencias y de la génesis de las normas sociales. Una perspectiva que sólo entienda la explicación social recurriendo a tipos individuales, difícilmente puede dar cuenta de las distintas racionalidades económicas de tramperos anglosajones e indios, por volver a un ejemplo ya apuntado.

\section{BIBLIOGRAFÍA}

ABELL, P. (1996), "Sociological Theory and Rational Choice Theory", Social Theory, Bryan S. Turner (ed.), Oxford, Blackwell Publishers Ltd.

AGUIAR, F., y A. de FRANCISCO (1999), "Racionalidad e identidad. Una crítica a Alessandro Pizzorno", Revista Internacional de Sociologia, $n^{\circ} 24$, pp. 77-93.

AGUIAR, F. (1993), “Confianza y racionalidad”, Problemas de teoria social contemporánea, en E. Lamo de Espinosa y J.E. Rodriguez Ibáñez, Madrid, Centro de Investigaciones Sociológicas.

ALONSO, L. E. y J. CALLEJO (1994), "Consumo e individualismo metodológico: una perspectiva crítica”, Politica y Sociedad, $n^{\circ}$ 16: 111-138.

BANNOCK, G., R.E. BAXTER y E. DAVIS (1992), The Penguin Dictionary of Economics, Londres, Penguins Books.

BECKER, G. S. ([1976a] 1980), "El enfoque económico del comportamiento humano”, Información Comercial Española, $n^{\circ} 557$.

(1976b), "Altruism, Egoism, and Genetic Fitness: Economics and Sociobiology", Journal of Political Economy, $\mathrm{n}^{\circ}$ 14(3), pp. 817-826.

([1971] 1977), Teoría económica, México, Fondo de Cultura Económica.

([1981] 1987), Tratado de la familia, Madrid, Alianza Universidad.

BEHRMAN, J.R., R.A. POLLAK y P. TAUBMAN (1995), From Parent to Child: IntrahouseHold Allocations and Intergenerational Relations in the United States, Chicago, University of Chicago Press.

BLAUG, M. ([1980] 1985), La metodologia de la economia, Madrid, Alianza Universidad.

BLOSSFELD, H.P. y G. PREIN (1998), (ed.). Rational Choice Theory and Large-Scale Data Analysis. Oxford, Westview Press. 
BLOSSFELD, H.P. (1996), "Macrosociology, Rational Choice Theory and Time. A Theoretical Perspective on the Empirical Analysis of Social Processes", European Journal of Sociology, $n^{o} 21(2), \mathrm{n}^{\circ} 181-204$.

BOUDON, R. ([1979] 1981), La lógica de lo social. Introducción al análisis sociológico, Madrid, Rialp.

(1996), "The 'Cognitive Model'. A Generalized 'Rational-Choice Model' ", Rationality and Society, $n^{\circ} 8(2)$, pp. 1231-50.

(1998a), "Social Mechanisms without Black Box", Social Mechanism. An Analytical Approach to Social Theory, en P. HEDSTRÖM y R. SWELDBERG (ed.), Cambridge, Cambridge University Press.

(1998b), "The Limits of Rational Choice", American Journal of Sociology, $n^{\circ} 104$ (3), 817828.

(1999), "Local vs. General Ideologies: A Normal Ingredient of Modern Political Life", Journal of Political Ideologies, $n^{\circ} 4(2)$, pp.141-161.

(2003), "Beyond Rational Choice Theory", Annual Review of Sociology, $n^{\circ} 29$, pp.1-21.

BOURDIEU, P. y L. WACQUANT (1992), An Invitation to Reflexive Sociology, Chicago, The University of Chicago Press.

BOURDIEU, P. ([1979] 1991), La distinción, Madrid, Taurus.

([1980a] 1991), El sentido práctico, Madrid, Taurus.

([1980b] 2000), “Una ciencia que molesta”, Cuestiones de sociología, Madrid, Istmo.

([1994] 1997), Razones prácticas, Barcelona, Anagrama.

([2000] 2003), Las Estructuras Sociales de la Economia, Barcelona, Anagrama.

(1983), entrevista publicada en Sociologisch týdschrift, Amsterdam, X, nº 2, 1983 (traducida en Cosas dichas).

BUNGE, M. ([1999] 2000), La relación entre la sociologia y la filosofia, Madrid, EDAF.

CARLING, A. (1986), "Rational Choice Marxism”, New Left Review, $n^{\circ} 160$, pp. 24-62.

COLEMAN, J.S. (1990), Foundations of Social Theory, Harvard, Harvard University Press.

CONLISK, J. (1996), 'Why Bounded Rationality?', Journal of Economic Literature, XXXIV(2).

COWEN, T. (1998), “Do Economist Use Social Mechanisms to Explain?”, Social Mechanism. An Analytical Approach to Social Theory, Peter Hedström y Richard Sweldberg (ed.), Cambridge, Cambridge University Press. 
RIS

REVISTA INTERNACIONAL DE SOCIOLOGIA

No 37, ENERO-ABRIL, 2004

EDLING, C. 2000. "Rational Choice Theory and Quantitative Analysis. A Comment on Goldthorpe's Sociological Alliance", European Sociological Review, 16, pp. 1-8.

ELSTER, J. ([1983] 1988), Uvas amargas, Madrid, Península.

([1984] 1989), Ulises y las sirenas ( $2^{\mathrm{a}}$ edición, $1^{\mathrm{a}}$ en 1979), Fondo de Cultura Económica, México.

(1986), (ed.), The Multiple Self, Cambridge, Cambridge University Press.

([1989a] 1991), Tuercas y tornillos, Barcelona, Gedisa.

([1989b] 1991), Juicios Salomónicos. Las limitaciones de la racionalidad como principio de decisión, Barcelona, Gedisa.

([1991] 1992), El cemento de la sociedad (2a edición, $1^{\text {a }}$ en 1989), Barcelona, Gedisa.

(1997), “More Than Enough", Chicago Journal of Law, nº 64 (2), pp. 749-64.

(2000), "Rational Choice History: A Case of Excessive Ambition", American Political Science Review, $n^{\circ} 94$, pp. 685-95.

(2002), Ulises desatado, Barcelona, Gedisa.

ENGLAND, P. (1993), "The Separative Self: Androcentric Bias in Neoclassical Assumptions", pp. 37-53, en editado por M.A. Ferber y A. Julie, Nelson, Beyond Economic Man, Chicago, University of Chicago Press.

ENGLAND, P. y S. KILBOURNE (1990), "Feminist Critique of the Separative Model of Self", Rationality and Society, $n^{\circ} 2$, pp. 156-71.

ETZIONI, A. (1990), “Towards a Deontological Socioeconomic", en Mark Lutz (ed.) Social Economics: Retrospect and Prospect, Boston, Kluwer.

EVANS-PRITCHARD, E.E. ([1937] 1976), Witchcraft, Oracles and Magic Amon the Azande, Oxford, Clarendon.

ESSER, H. (1996), "What is wrong with 'Variable Sociology'?", European Sociological Review, 22, pp. 159-66.

FRANKFURT, H. (1971), "Freedom of the Will and the Concept of a Person", Journal of Philosophy, $\mathrm{n}^{\circ} 68$, pp. 11-25.

FRIEDMAN, M. (1953), “The Methodology of Positive Economics", M. Friedman Essays in Positive Economics, Chicago, University of Chicago Press.

GIL CALVO, E. (1993), "La hipótesis del rol 'egoista'. Límites de la teoria de la elección racional" Emilio Lamo y José E. Rodríguez (ed.) Problemas de teoria social contemporánea, Madrid. CIS

170 
GODELIER, M. ([1966] 1970), Racionalidad e irracionalidad en economia, México, Siglo XXI: ([1984] 1989), Lo ideal y lo material, Madrid, Taurus.

GOLDTHORPE, J. H. (1997), "The Integration of Sociological Research and Theory. Grounds for Optimism at the End of The Twentieth Century", Rationality and Society, $n^{\circ} 9(4)$, pp. 407-27.

(1998a), "Rational action theory for sociology", British Journal of Sociology, nº 49 (2): 167-192.

(1998b), "The Quantitative analysis of Large-Scale Data Sets and Rational Action Theory: for a Sociological Alliance", en Hans-Peter Blossfeld and Gerald Prein (ed.) Rational Choice Theory and Large-Scale Data Analysis, Oxford, Westview Press.

GONZÁLEZ LEÓN, R. (1996), "Dinero y acción racional según L. von Mises", Politica y Sociedad, $n^{\circ} 21$, pp. 9-22.

GRIGNON, C. ([1998] 2000), "Las ciencias del relato y la formalización”, Témpora, n 3,"enerodiciembre, pp.13-37.

HABERMAS, H. ([1970] 1988), La lógica de las ciencias sociales, Madrid, Tecnos.

HARSANYI, J. (1955), "Cardinal Welfare, Individualistic Ethics, and Interpersoanl Compaisions of Utility", Journal of Political Economy, $n^{o}$ 63, pp. 309-321.

HAUSMAN, D. M. (1992), The Inexact and Separate Science of Economics, Cambridge, Cambridge University Press.

HEATH, A. (1976), Rational Choice and Social Exchange, Cambridge, Cambridge University Press.

HECHTER, M. y S. KANAZAWA (1997), "Sociological Rational Choice Theory”, Annual Review of Sociology, $n^{\circ} 23, \mathrm{pp} .191-214$.

HEDSTRÖM, P. y R. SWEDBERG (1998), "Rational Choice, Situational Analysis, and Empirical Research", H-P. BLOSSFELD and G. PREIN (ed.), Rational Choice Theory and Large-Scale Data Analysis, Oxford, Westview Press.

HERNES, G. (1992), "We are Smarter than We Think", Rationality and Society, $n^{\circ} 4$, pp. 421-436.

HIRSCHLEIFER, J. (1985), “The Expanding Domain of Economics”, American Economic Review, $n^{\circ} 75$, pp. 53-68.

HOLLIS, M. ([1994] 1998), La filosofia de las ciencias sociales, Barcelona, Ariel.

(1977), Models of Man: Philosophical Thoughts on Social Action, Cambridge, Cambridge University Press.

IBÁÑEZ, J. (1988), “Las medidas de la sociedad”, REIS, nº 29, pp. 85-128. 
RIS

REVISTA INTERNACIONAL DE SOCIOLOCÍA

No 37, ENERO-ABRIL, 2004

JOSÉ SATURNINO MARTÍNEZ GARCIA

ISHIDA, J. (2003), "The Role of Intrahousehold Bargaininig in Gender Discrimination", Rationality \& Society, $n^{\circ} 15(3)$, pp. 361-380.

KAHNEMAN, D. y A. TVERSKY (1982), "Psicología de las preferencias", Investigación y Ciencia, $n^{\circ}$ 66, pp. 62-74.

KANAZAWA, S. (2001), “De Gustibus Est Disputandum”, Social Forces, 79, pp. 113-163.

KIMMEL, M. S. (2000), The Gendered Society, Oxford, Oxford University Press.

LEVINE, A., E. SOBER y E.O. WRIGHT ([1986] 1989), "Marxismo e individualismo metodológico", traducido en Zona Abierta, $n^{\circ}$ 41-42, pp.132-57.

LINDENBERG, S. (1996), "Choice-Centred Versus Subject-Centred Theories in the Social Sciences: The Influence of Simplification on Explananda", European Sociological Review, n ${ }^{\circ} 12$, pp.147-57.

LIZÓN, A. (2000), “Del ‘Efecto Simmel'y la autopersuasión: La teoría cognitivista de las creencias de R. Boudon", Papers, $n^{\circ}$ 62, pp. 53-80.

MACY, M. y A. FACHE (1995), "Beyond rationality in models of choice", Review of Sociology, 73-92.

MARGOLIS, H. (1982), Selfishness, Altruism, and Rationality, A Theory of Social Choice, Cambridge, Cambridge University Press.

MARTÍNEZ VEIGA, U. (1990), Antropología económica, Barcelona, Icaria.

McCLOSKEY, D. ([1985] 1990), La retórica de la economia, Madrid, Alianza.

MOUZELIS, N. (1995), Sociological Theory: What Went Wrong? Diagnosis and Remedies, London, Roudledge.

MUNDÓ, J. y D. RAVENTÓS (2000), "Fundamentos cognitivo-evolucionarios de las ciencias sociales", Revista Internacional de Sociología, $\mathrm{n}^{\circ}$ 25, pp. 47-74.

NORKUS, Z. (2000), “Max Weber's Interpretive Sociology and Rational Choice Approach”, Rationality and Society, $n^{\circ} 12$, pp. 259-82.

OPP, K.D. (1998), "Can and Should Rational Choice Theory Be Test by Survey Research? The Example of Explaining Collective Political Action", en editado por H-P. Blossfeld y G. Prein, Oxford, Rational Choice Theory and Large-Scale Data Analysis, Westview Press.

RABIN, M. (1998), "Psychology and Economics”, Journal of Economic Literature, XXXVI, pp. 11-46.

ROEMER, J.E. (1986), Analytical Marxism. Studies in Marxism and Social Theory, Cambridge, Cambridge University Press.

ROSENBERG, A. (1992), Economics. Mathematical Politics or Science of Diminishing Returns?, Chicago, The University of Chicago Press. 
SACKS, O. ([1994] 1997), Un antropólogo en Marte, Barcelona, Anagrama.

SAHLINS, M. ([1972] 1977), Economía de la edad de piedra, Madrid, Akal.

SÁNCHEZ-CUENCA, I. (1996), Preferencias, mecanografiado. Departamento de Sociología. Universidad de Salamanca.

SANTAMARÍA, C. (1995), Introducción al razonamiento humano, Madrid, Alianza.

SCHELLING, Th.C. ([1977] 1989), Micromotivos y Macroconductas, México, Fondo de Cultura Económica.

SEARLE, J.R. ([1995] 1997), La construcción de la realidad social, Barcelona, Paidós.

SEN, A. K. ([1970] 1976), Elección colectiva y bienestar social, Madrid, Alianza Editorial.

([1977] 1986), "Los tontos racionales", en F. Hahn y M. Hollis (eds.), [e.o.1979], Filosofia y teoría económica, México, Fondo de Cultura Económica.

STINCHCOMBIE, A.L. (1968), Constructing Social Theories, Nueva York, Harcourt Brace.

SWEDBERG, R. (1990), Economics and Sociology, Princeton, Princeton University Press.

ULTEE, W.C. (1996), "Do Rational Choice Approaches have Problems?", European Journal of Sociology, $n^{\circ} 21(2)$, pp. 165-79.

VAN PARIJS, P. (1990), Le modèle économique et ses rivaux, Ginebra, Droz.

WEBER, M. ([1922] 1984), Economia y sociedad, México, Fondo de Cultura Económica.

ZAFIROVSKI, M. (1999), "What is Really Rational Choice? Beyond the Utilitarian Concept of Rationality", Current Sociology, $n^{\circ}$ 47(1), pp. 47-113.

(2000), "Extending the Rational Choice Model From the Economy to Society", Economy and Society, $n^{\circ} 20$, pp.181-206. 